Mass media attention to welfare state reforms:

Evidence from Britain, 1996-2014

\author{
Carsten Jensen \\ Department of Political Science \\ Aarhus University \\ Bartholins Alle 7 \\ 8000 Aarhus C \\ Mail: carstenj@ps.au.dk \\ Phone: +4587165678 \\ Seonghui Lee \\ Department of Political Science \\ Aarhus University \\ Bartholins Alle 7 \\ 8000 Aarhus C \\ Mail: slee@ps.au.dk \\ Phone: +4587166224
}




\section{Mass media attention to welfare state reforms: evidence from Britain, 1996-2014}

One of the core questions facing political scientists is how politicians are able to implement cutbacks without suffering electoral backlash. Welfare programmes tend to be highly popular among the public, who typically favour expanding public spending and entitlements over cutbacks (Jæger 2011; van Oorschot 2006). Given the conventional wisdom that cutbacks are risky for reelection-motivated politicians, it is surprising that cutbacks actually occur quite frequently (e.g. Allan and Scruggs 2004; Clasen and Clegg 2007; Korpi and Palme 2003). Scholars have been preoccupied with aligning these two observations - the popularity of welfare programmes and frequently occurring cutbacks - for the past couple of decades.

One attempt at solving the puzzle has been to question whether all voters are equally opposed to cutbacks all the time. Armingeon and Giger (2008) show how cutbacks only cost votes for the incumbent government if the welfare state has been high on the election campaign agenda; if politicians are able to keep reforms off the agenda, they suffer no electoral backlash. In another article, Giger and Nelson (2013) show that many voters are so-called conditional believers of the welfare state, meaning that they cherish both a sound economy and generous welfare. Such conditional voters may accept cutbacks when framed as economic necessities. This voter perspective offers a plausible solution to the puzzle of welfare state cutbacks without electoral punishment.

That said, there has yet to be any systematic test of what would appear to be the most straightforward 'broken link' between the actions of politicians and the reactions of voters: the mass media. The mass media (frequently) failing to report on reform might explain why voters do not respond to otherwise unpopular legislation (Pierson 1994). To probe if this is the case, we construct two monthly datasets covering the period 1996-2014 in Britain. One contains information 
on all of the changes to old age pensions and unemployment protection passed by the British Parliament, while the other contains information on all of the articles published in The Times on these two areas. With this data in hand, it is possible to test if the mass media normally report on welfare reform and, if so, whether they prioritise expansions or cutbacks.

The next section outlines the puzzle in greater detail and the answers to it in the existing literature. The subsequent section discusses what we know about the role of the mass media in the politics of the welfare state (not a lot) and in political communication more broadly (quite a bit) - and what these existing insights lead us to expect regarding welfare state reform and mass media attention. On this basis, the rest of the paper concerns itself with the empirical setup and findings. We begin by detailing our data collection efforts and statistical estimation strategy and then present the results. Our findings are clear-cut: cutbacks generate increased attention - and do so for both old age pensions and unemployment protection - whereas expansions have no effect on mass media attention. We also find that cutbacks that are relatively easy to comprehend for ordinary citizens (e.g. a cut in nominal benefits) are reported more frequently than more technical cutbacks (e.g. changes to how benefits are indexed).

\section{The puzzle of welfare state reforms}

It has been repeatedly documented how voters are generally supportive of the welfare state. Large majorities agree that the government is responsible for ensuring adequate living conditions for the old and jobless and healthcare for the sick; and similarly sized majorities typically believe that the government ought to spend more on welfare programmes protecting against such social risks (e.g. Jæger 2011; van Oorschot 2006). This is also true for citizens in Anglo-Saxon countries, who are supposedly less pro-welfare than citizens in Continental Europe and Scandinavia. Looking at Britain, the country in focus in this article, the British Social Attitudes Survey documents that the proportion of Britons wanting to spend less on the welfare state in order to reduce taxation has 
never surpassed $10 \%$ since polling began in 1983 . By 2016 , fully $48 \%$ wanted the government to spend more on welfare, while fewer than 5\% wanted cuts (Curtice 2017: 1-2).

This popularity has informed much research in the welfare state literature, perhaps most notably Pierson's 'new politics' argument $(1994 ; 1996 ; 2001)$. The basic thrust of the new politics argument is that voters, due to their support for the welfare state, will punish any politician trying to implement cutbacks; if anything, voters prefer better welfare rather than sticking to the status quo. Since fiscal constraints rule out substantial expansion, politicians are left in a difficult situation, the most appropriate course of action often simply being to do nothing. The politicians hereby avoid annoying the electorate and, with a bit of luck, the economy remains afloat until they themselves are no longer in politics; in short, welfare state policymaking is all about avoiding blame.

The new politics argument has been criticised for overlooking how the past decades have witnessed many and sometimes very major reforms. Korpi and Palme (2003) and Allan and Scruggs (2004) introduce two large-N datasets covering citizens' social rights related to old age, unemployment, and sickness in 18 countries since the 1930s and 1970s, respectively. The two datasets were collected independently of each other but yielded largely identical findings in terms of the broad development of the welfare state. The welfare state continued to expand through the 1970s and into the 1980s, after which came a period of significant decline. Using more in-depth analysis or newer data, many other scholars have reached similar conclusions (e.g. Clasen and Clegg 2007; Jensen 2014). The substantial cutbacks since the 1980s, albeit to varying degrees and speeds in different countries, are by now a settled fact. This leaves us with a puzzle: why do voters who are supportive of the welfare state refrain from punishing the politicians who scale it back?

Giger and her collaborators have promoted a voter perspective to answer this puzzle. Giger and Nelson (2011) show how the effect of changing social rights on an incumbent government's vote share in the next election is minuscule; to the extent the effect is visible at all, it 
only relates to a small number of parties. Armingeon and Giger (2008) moderate this by showing that punishment is more widespread if the welfare state was an important topic during the election campaign. Conversely, if politicians are able to keep the topic off the campaign agenda, they will be able to reform the welfare state without suffering electoral consequences. Finally, Giger and Nelson (2013) show that voters' preferences are somewhat muddier than the new politics approach appears to assume. While a clear majority indeed favours a generous welfare state, a segment of these welfare supporters also feel strongly about a sound economy. The authors speculate that the conditional supporters are important to reform-minded politicians because they are presumably willing to be persuaded to support cuts if reforms are framed as necessary for fiscal health.

While the existing literature has provided substantial insights into the politics of the welfare state, it has a glaring shortcoming: an almost total neglect of the mass media (with a few exceptions, as returned to below). It is obviously unrealistic to assume - and to our knowledge no scholars do so - that voters themselves keep track of which laws pass in parliament. Instead, the implicit assumption of the literature is that information flows via the mass media to the voters. This is indeed the premise of the new politics perspective, as most explicitly formulated by Pierson (1994: 21), '[r]eforms are less likely to generate a popular outcry if television reporters cannot explain the implications of the new policies in fifteen seconds or less'. The point here is straightforward: if the mass media do not report on reforms, voters will be unable to realise what goes on and punish the politicians accordingly. This entails that knowing whether and under what conditions the mass media report on welfare state reforms becomes vital.

\section{Welfare state reforms in the news}

There is anecdotal evidence that the mass media cover welfare state reforms. Public uproar in 2010 over the proposed overhaul of the National Health System, for instance, forced the British Conservatives to retreat and to put their reform agenda on hold (Jensen 2014: 90). In the 1990s, a 
Social Democrat-led government in Denmark was similarly successful in introducing a string of reforms but experienced a media storm after mishandling an early retirement reform, leading to a dramatic drop in its polling numbers (Elmelund-Præstekær et al. 2015: 441). Such mass media attention is normally viewed in the literature as resulting from government miscalculations or the strategic opportunism of the opposition. Lindbom (2010) takes the reverse view and shows why the comparably significant Swedish housing reform in the 1990s did not receive mass media attention. Armingeon and Giger (2008) suggest that the variation in the mass media attention to welfare state reform is conditional: if welfare is high on the election campaign agenda (as measured by party manifestos), it might also be high on the agenda of the mass media.

Its qualities untold, extant work on the mass media and welfare state reform suffers from three important problems. First, Lindbom's article alone explicitly studies the mass media, whereas others rely on impressionistic accounts of mass media coverage to buttress their main analysis (focusing normally on the relationship between welfare state reform and voter reactions). To our knowledge, none has conducted a more systematic empirical study correlating welfare state reforms with mass media attention. This is needed if we want to move beyond anecdotal evidence and provide a solid answer to the core question presented here: do the mass media report on welfare state reforms?

Second, the existing work almost exclusively assumes that welfare state reform is synonymous with cutbacks. Nevertheless, even in the 'era of permanent fiscal austerity', as Pierson (2001) coined it, expansion occurs. For example, British old age pension and unemployment protection programmes saw almost the same number of cuts and expansions in the 1996-2014 period under study in this paper - although not to the same extent in the two programmes (most of the cuts were made to unemployment protection, whereas most of the expansions were to old age pensions). This is not to belittle the substantial rollback in many quarters of the welfare state, which is well documented, but to highlight how this has been anything but a unidirectional process. In 
Pierson's terminology, there have been numerous credit-claiming opportunities over the years. This is interesting from the perspective of our analysis, because it highlights a second question: do the mass media report cutbacks and expansions equally, or do they prioritise one over the other?

Third, most citizens do not follow politics very closely in their everyday life. In the welfare state literature, this has inspired the argument that politicians try to obfuscate cutbacks by using so-called 'invisible' policy instruments; that is, policy instruments that are highly technical and therefore less likely to attract media attention (Pierson 1994: 21). An example of a 'visible' cutback would be a reduction of nominal benefits from, say, $£ 1000$ to $£ 800$ per month. Such cuts are easy to understand because the money going into the claimant's account drops so unmistakably. An example of an 'invisible' cutback is a change in the indexation rules whereby benefits are gradually eroded by inflation. Importantly, it has never been tested if the visibility of policy instruments affects mass media attention. This leads to a third question: do the mass media report equally on 'visible' and 'invisible' policy instruments?

Turning to the broader - and voluminous - literature on the determinants of mass media attention, we find two contradicting expectations on the matter of whether the mass media would react to welfare state reforms. One important news criterion is that news stories should be relevant for mass media consumers (Gans 1979: 151; Golding and Elliot 1979: 117-118), which the welfare state certainly is. The welfare state is not only popular, but invariably among the most important issues that politicians ought to deal with, according to the voters (e.g. Aardal and Wijnen 2005). This speaks in favour of expecting the mass media to notice welfare state reforms. But such reforms - even so-called 'visible' policy instruments - are also relatively complicated, and the mass media tend to avoid reporting on issues that are not easy to communicate (Pierson 1994: 21). Another reason for not reporting on welfare state reform is that the effects are typically first felt some time down the road. This makes welfare state reforms very different from news about economic indicators (e.g. the unemployment rate, consumer confidence), which are much closer to 
the here-and-now, everyday experience of citizens. ${ }^{1}$ Overall, it is therefore difficult to deduce in advance which of these counter-balancing concerns will dominate the basic question of there being any mass media reaction at all to welfare state reform.

We therefore hypothesise the most basic question of whether the mass media report on welfare reforms at all. The relevance criterion leads us to expect that there will be a positive reaction $(\mathrm{H} 1)$; alternatively, the simplicity criterion leads us to expect no reaction $(\mathrm{H} 2)$.

H1 RELEVANCE: Welfare state reforms will get mass media attention.

H2 SIMPLICITY: Welfare state reforms will not get mass media attention.

If we nevertheless assume that the mass media will report on welfare state reform, it is easier to deduce expectations regarding the second question; i.e. if there will be equal attention to both cutbacks and expansions. Negativity is among the best-documented news criteria (Shoemaker and Reese 2013: 53-54; Soroka 2014: 72-94), and several studies have shown how the mass media tend to report bad news much more than good news. Fogarty (2005) and Soroka (2006), for instance, conclude that negative information about the economy (e.g. rising unemployment) generates considerably more mass media attention than a comparable decline in unemployment. If a similar negativity bias exists for news on welfare state reform, we may expect cutbacks to lead to more mass media attention than expansions.

\footnotetext{
${ }^{1}$ In this vein, some might think that benefit recipients will be more aware of reforms than the rest of the population. This subset of the public may, hence, realize reforms already as they happen and, if nothing else, notice the consequences when they are implemented. From an aggregated perspective, however, this is more a matter of degree: the basic proposition that people do not keep track of legislative changes still appears to be the realistic default assumption. Ultimately, the relative awareness of reforms is an empirical question that is beyond the scope of this paper to explore.
} 
H3 NEGATIVITY: Cutbacks will get more mass media attention than expansions.

As explained in the data section below, we explore media attention to two separate welfare policy domains: old age pensions and unemployment protection. The former is relevant to a large group of people and their families, whereas joblessness concerns a smaller and perhaps more marginalised group. This difference might affect mass media attention, as one of the news criteria is the relevance of an event to a large audience (Gans 1979: 151). Conversely, the divided public opinion on unemployment protection could amplify attention to the issue. By way of analogy, the strong polarisation of public opinion on issues such as climate change and same-sex marriage renders them newsworthy for the mass media, even though they are not directly relevant in the everyday lives of most people; in short, conflict sells (Golding and Elliott 1979: 115). Integrating the negativity hypothesis with the discussion about cross-programme differences in relevance and 'conflictualness', there are reasons to expect equally strong effects for both old age pension and unemployment protection cutbacks, whereas expansions will witness equally limited effects.

H4 NEGATIVITY + CROSS-PROGRAMME: Cutbacks in old age pensions and unemployment protection will get strong mass media attention, whereas expansions will get limited mass media attention.

Moving on, drawing on both the simplicity and negativity news criteria, developing an argument about how the mass media will report on reforms with different degrees of visibility appears straightforward. If the mass media truly shy away from complicated news stories in general and focus more on negative stories than positive stories, we may deduce that highly 'visible' and negative news stories will get more attention than 'invisible' and negative stories (let alone positive stories). We therefore expect the mass media to pay particular attention to 'visible' cutbacks. 
H5 SIMLICITY + NEGATIVITY: 'Visible' cutbacks will get more mass media attention than ‘invisible’ cutbacks.

\section{Data and estimation strategy}

To test the effect of welfare state reforms on mass media attention in Britain, we construct two datasets covering the period 1996-2014. Britain is a good case for the current purpose; for one thing, it is well researched, meaning that we have a solid understanding of its welfare state and politics more broadly. Britain is also a prime example of a so-called liberal welfare state, with relatively limited generosity and public support (Esping-Andersen 1990). All else equal, this makes the welfare state a less sensitive political topic than in many other European countries. This makes it more likely that any effects observed here are transferable to other European countries.

The first dataset contains information on legislative changes to old age pensions and unemployment protection entitlements. The two programmes are selected for two reasons. First, they are at the core of what is conventionally understood as 'the welfare state' and, consequently, prominently featured in a very long list of publications on the politics of the welfare state. Second, both programmes are transfer schemes, meaning that we can code them using the same coding scheme, which is important for comparison. For the dataset, we code the legislative changes (what we call reform events) relating to any of the following 13 aspects of citizens' social rights:

1. Qualification period: How long does it take to become eligible?

2. Contribution period: How long must a person contribute to a scheme before becoming eligible?

3. Contribution level: How much must a person contribute?

4. Waiting period: How long after a social risk occurs before a person is eligible?

5. Age brackets: How old must a person be to become eligible?

6. Means test: Is there a means test? 
7. Duration period: How long can a recipient receive benefits?

8. Benefit level: Nominal value. What is the nominal value of the benefits?

9. Benefit level: Indexation rule. Are the nominal benefits automatically regulated and with what factor?

10. Benefit level: Assessment base. Has the base for calculating benefits changed?

11. Employability: Are recipients required to or offered the opportunity to voluntarily participate in activities meant to increase the likelihood of finding employment?

12. Health documentation: Is the recipient required to document their inability to work?

13. Residence: Does it matter where and under what circumstances the recipient lives?

For each of the 13 dimensions, we identified whether the reform event implied a cutback or expansion in citizens' social rights or if the reform event did not alter social rights in any specific direction (status quo). To gather information about reform events, we collected as many secondary sources as possible and supplemented them with extensive searches in legislative databases, which allowed us to systematically crosscheck almost all of the reform events. In total, we coded 89 reform events, of which 41 were expansions, 42 cutbacks, and six maintained the status quo. Several of the reform events happened in the same months. Overall, then, only 38 months witnessed reform events, whereas 190 months did not.

Following Jensen et al. (2017), we organise the 13 policy instruments into an ordinal scale measuring the degree of visibility. Indexation (no. 9) and assessment base (no. 10) are coded as 'clearly invisible'; qualification period (no. 1) and contribution periods (no. 2) are coded as 'quite invisible'; contribution level (no. 3) and waiting period (no. 4), health documentation (no. 12), and residence (no. 13) are 'in-between'; duration period (no. 7), employability (no. 11), and means testing (no. 6) are 'quite visible'; and changes in nominal benefits level (no. 8) and age brackets (no. 5) are 'clearly visible'. The ordinal scale is constructed so that $1=$ 'clearly invisible', $2=$ 'quite invisible', 3 = 'in-between', 4 = 'quite visible', and $5=$ 'clearly visible'. Table 1 provides a breakdown of the reform event variable. 
TABLE 1. Summary of reform events, monthly

\begin{tabular}{|c|c|c|c|c|c|c|c|c|c|c|}
\hline \multirow{3}{*}{$\begin{array}{l}\text { Number } \\
\text { of } \\
\text { reforms }\end{array}$} & \multicolumn{2}{|c|}{ Overall } & \multicolumn{2}{|c|}{ By policy domain } & \multicolumn{6}{|c|}{ By direction and visibility* } \\
\hline & \multirow[b]{2}{*}{ (freq.) } & \multirow[b]{2}{*}{$(\%)$} & \multirow{2}{*}{$\begin{array}{c}\text { Old age } \\
\text { pensions } \\
\text { (freq.) }\end{array}$} & \multirow{2}{*}{$\begin{array}{l}\text { Unemploy } \\
\text { ment } \\
\text { protection } \\
\text { (freq.) }\end{array}$} & \multicolumn{3}{|c|}{$\begin{array}{l}\text { Expansions } \\
\text { (freq.) }\end{array}$} & \multicolumn{3}{|c|}{$\begin{array}{c}\text { Cutbacks } \\
\text { (freq.) }\end{array}$} \\
\hline & & & & & All & Visible & Invisible & All & Visible & Invisible \\
\hline 0 & 190 & 83.33 & 204 & 208 & 205 & 214 & 225 & 205 & 210 & 223 \\
\hline 1 & 22 & 9.65 & 14 & 14 & 16 & 10 & 2 & 16 & 15 & 5 \\
\hline 2 & 5 & 2.19 & 3 & 3 & 3 & 3 & 0 & 4 & 2 & 0 \\
\hline 3 & 5 & 2.19 & 5 & 1 & 1 & 1 & 1 & 1 & 0 & 0 \\
\hline 4 & 2 & 0.88 & 0 & 1 & 2 & 0 & 0 & 1 & 1 & 0 \\
\hline 5 & 1 & 0.44 & 2 & 0 & 1 & 0 & 0 & 1 & 0 & 0 \\
\hline 6 & 3 & 1.32 & 0 & 1 & 0 & 0 & 0 & 0 & 0 & 0 \\
\hline $\begin{array}{c}\begin{array}{c}\text { Total } \\
\text { (months) }\end{array} \\
\end{array}$ & 228 & 100 & 228 & 228 & 228 & 228 & 228 & 228 & 228 & 228 \\
\hline
\end{tabular}

* Status quo reforms (a category under direction) and in-between reforms (a category under visibility) are not included in the table. For simplicity, the 'visible' category in the table includes 'quite visible' and 'clearly visible' reforms, while 'invisible' includes 'quite invisible' and 'clearly invisible' in the original coding.

Moving to the second dataset, we build two measures of mass media attention to old age pensions and unemployment protection, respectively (corresponding to our reform event data). We use news articles published in The Times as our measure of attention. The Times is a highquality broadsheet and frequently used in studies of mass media attention in Britain (see, e.g., John et al. 2013; Soroka 2006). It is widely read and politically centrist, meaning that it is a good proxy for overall mass media attention. Access to full-text, electronically searchable news articles is also particularly good for The Times, going back to 1996 in Factiva, a search engine run by Dow Jones \& Company. We employed a two-stage coding strategy. The first stage was a keyword-based search among all domestic news articles. ${ }^{2,3}$ This generated a pool of news articles, which we hand-

\footnotetext{
${ }^{2}$ By definition, 'domestic news' in Factiva indicates news reports about '[a]ctivities associated with governance at the national, regional or local level', and includes news about 'legislative, executive and judicial issues in addition to debate or conflict regarding laws, policies and governance' and 'opinion polls and referendums'.

${ }^{3}$ Factiva allows us to filter news articles that meet multiple criteria simultaneously. In this first step, we filtered news articles that have more than 150 words AND contain at least one of the following words or phrases in its first 50 words: unemployment, employment, welfare, reform, social security, pensions, retirement, national insurance, regulations, benefits, provisions, child additions, payments, income,
} 
coded in the next stage to ensure that each of them explicitly concerned either old age pensions or unemployment protection (or, in a few instances, both). This two-stage process produced 1669 relevant news articles.

With this data in hand, we can construct two measures of mass media attention: the absolute number of news articles on old age pensions and unemployment protection in a given month as well as the percentage of these articles relative to all domestic ones. The percentage measure is probably the theoretically most accurate, because it captures by design that overall societal attention is finite: if attention to one issue goes up, attention to another has to go down accordingly. This mathematical property of the percentage measure intuitively reflects the observation in existing research that the mass media (or the public and politicians for that matter) is only able to pay attention to a limited number of issues at a time (Jones et al. 2003; Jones and Baumgartner 2005). While the absolute number is less precise, it is easier to interpret, so we also report results for this measure (and as will be evident shortly, the findings are by-and-large identical, which is due to the total number of all domestic articles being relatively stable). The number of news articles varies from zero to 40 per month (with a median of 6/month); and the share of such news varies from $0.01-0.36 \%$ out of the entire volume of domestic news (with a median of $0.06 \%$ ). Panel $\mathrm{A}$ in the top of Figure 1 displays the trend in the media attention using the two measures.

disqualification period, wage, labor market, implementation, poverty, lone parents, earnings, entitlements, or savings. 
FIGURE 1. Time series in the media attention (The Times, 1996-2014)

A. Trend in the number and percentage of welfare news

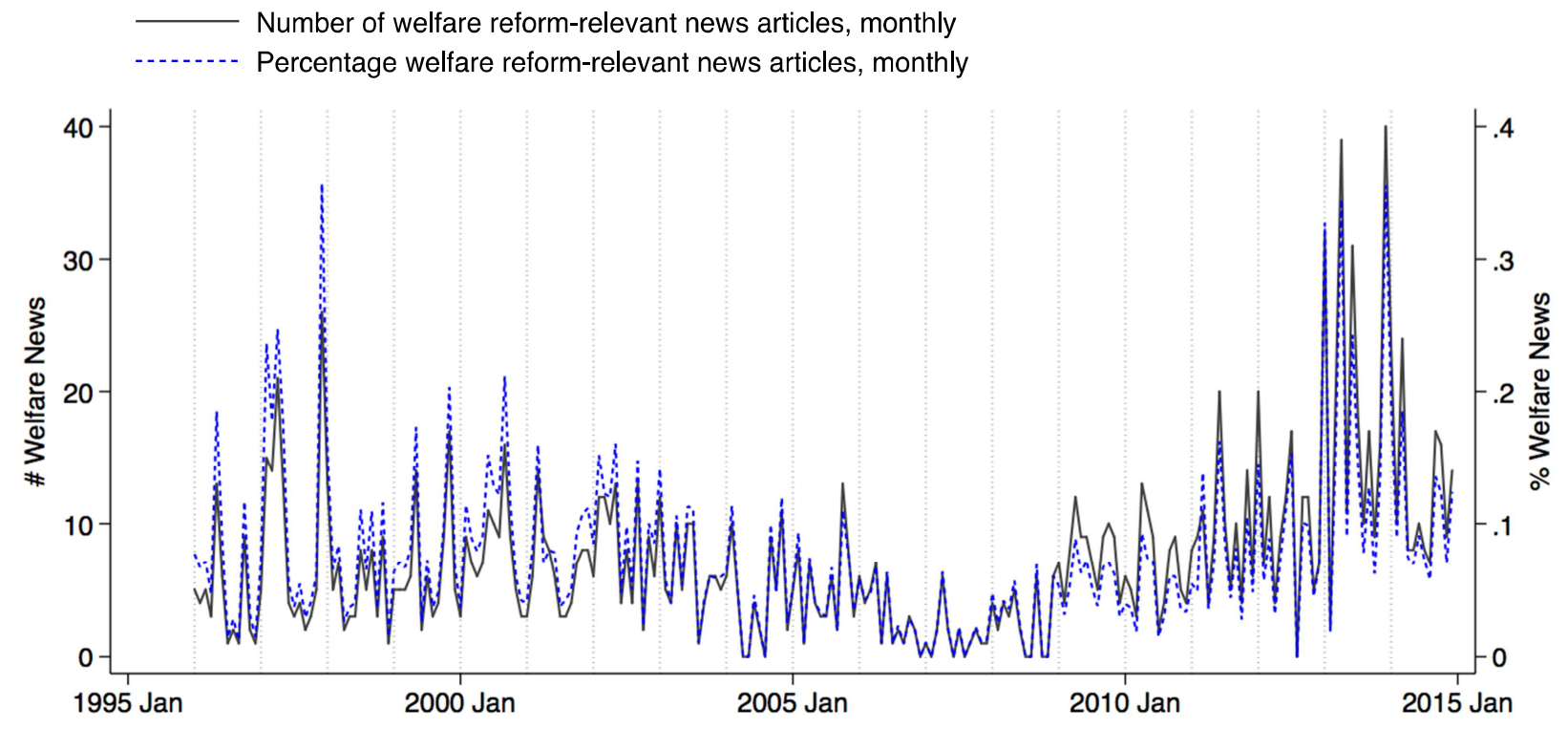

B. First differences in the number and percent of welfare news

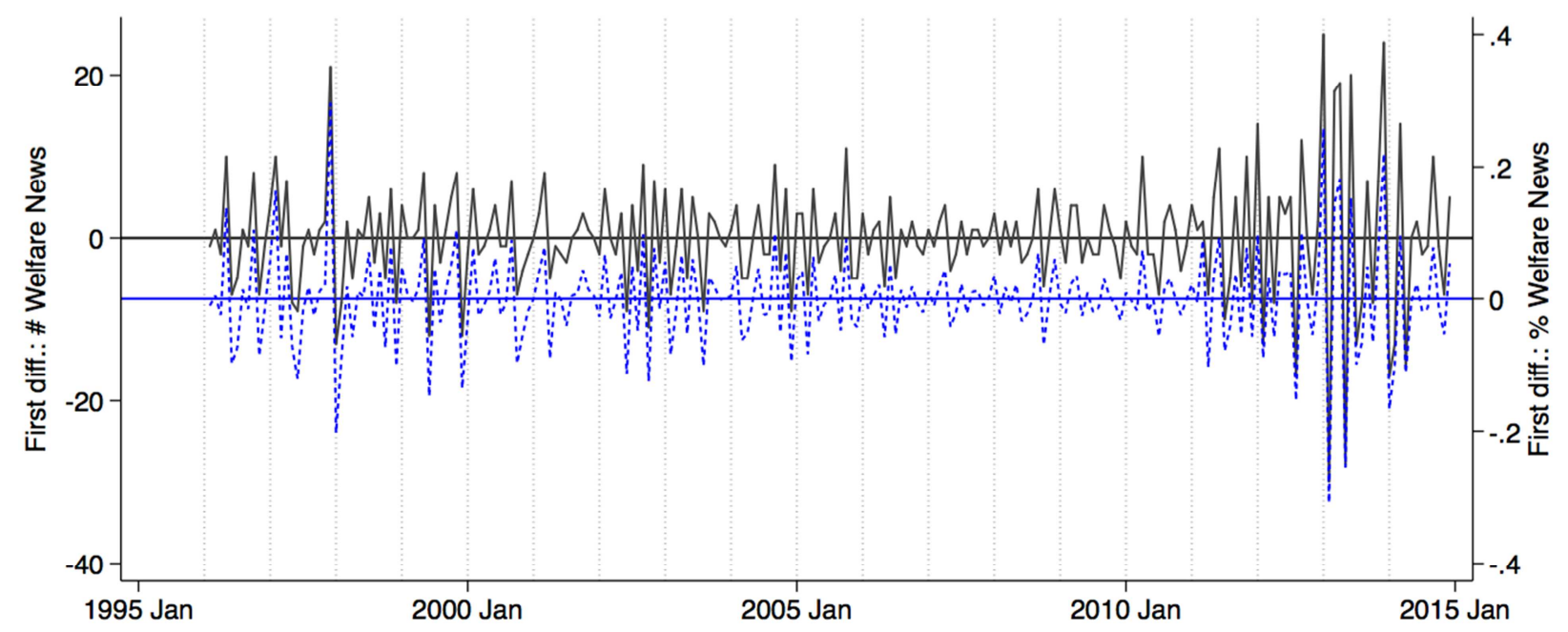

The means of the data series displayed in Panel A change over time - first being relatively high in the late 1990s and early 2000s, dropping for the rest of the decade, and then surging again after 2010. In statistical terms, this implies that the dependent variables in our analysis are non-stationary, which is a serious problem in a time series analysis like the one we intend to perform. The standard remedy against non-stationarity is to take the first difference of the 
variable of interest; that is, to calculate the change from one period to another, and then use this measure as the dependent variable (Gujarati 2003: 820). We opt for this solution. Panel B in the bottom of Figure 1 displays the first difference in the two attention measures. In substantial terms, this procedure also makes sense if we assume that there is a default baseline of welfare-related news regardless of welfare state reforms occurring or not. Our first difference measures allow us to see how welfare state reform creates a deviation from that baseline.

The explanatory variable in the analysis is the monthly reform event data described above. Here again, we calculate the first difference. The reason for doing so is theoretical. Much research documents how novelty is a key news criterion. As one scholar observes, 'above all else, reporters are taught to search what is new and different in events of the past twenty-four hours' (Patterson 1994: 60). In line with this, Matthews et al. (2012) find that mass media coverage of campaign-period polls increases with poll volatility. Similarly, Soroka et al. (2015) show that reporting on the economy is driven largely by changes in the economic indicators rather than the absolute levels of the indicators: a change in the unemployment rate is more likely to be reported than the level of unemployment. Following this logic, we also look at the changes in reform activity. In our case, of course, the difference between the two measures is not great because there are so many months without any reform events. If there was no reform event in the month before, the change in the number of reform events will be equal to the sheer number of reform events in the given month. Still, we stick to the theoretically more precise measure while noting that we reproduce the substantial findings reported below with the levels measure as well.

Both of the measures for the dependent variable show considerable autocorrelation and time dependency, while the main explanatory variable, the number of reform events, does not. Specifically, preliminary tests suggest that three (or four) lags are necessary to account for the 
autocorrelation in the media data. ${ }^{4}$ We therefore include three lagged dependent variables $(\mathrm{t}-1, \mathrm{t}-2$, t-3) in our model. Closer scrutiny of the mass media data series reveals clear patterns of seasonality; that is, systematic fluctuations across the year in attention to old age pensions and unemployment protection. August, for instance, is always a very slow month with very little attention, presumably due to the parliamentary recess beginning in late July and ending in early September. We account for this seasonality in two ways. First, we include the value in the same month in the last year (t-12), and, second, we include monthly dummy variables (with January as the baseline). Taken together, we model the current change in mass media attention as a function of past changes in mass media attention, current changes in reform events, seasonality, and an error component.

$$
\Delta \text { Media }_{\mathrm{t}}=\alpha_{1}+\Delta \text { Reform }_{\mathrm{t}}+\Delta \text { Media }_{\mathrm{t}-1}+\Delta \text { Media }_{\mathrm{t}-2}+\Delta \text { Media }_{\mathrm{t}-3}+\text { Seasonality }+\varepsilon_{1}
$$

Note that we do not lag the reform event variable, because we assume that the mass media quickly (i.e. within a month) report on the events. Based on the extant research on news reporting discussed above, this seems a highly reasonable choice. It is also worth noting that we do not include any controls in the model apart from the three lagged dependent variables and seasonality. Given the setup, it is very difficult to see which unobserved factors plausibly and strictly within the timespan of a single month can affect both changes in reform events, which always take much longer than a month to prepare and legislate, and changes in mass media attention. We have experimented with different controls, such as the unemployment rate, and they did not alter the results. But since there is no clear theoretical justification for including them, the models we report below stick to the baseline model we have outlined here.

\footnotetext{
${ }^{4}$ For example, when we estimate autoregressive models for the percentage of welfare news, $\mathrm{R}^{2}$ increases from 0.096 in $\mathrm{AR}(1)$ to 0.158 in $\mathrm{AR}(3)$, and to 0.162 in $\mathrm{AR}(4)$. Our tests also suggest that the lagged changes in media attention to welfare reforms (from t-1 to t-3) are useful predictors of current change in media attention to welfare, with $\mathrm{R}^{2}$ increased from 0.205 to 0.314 by adding lags 2 and 3 to a model that only includes the lagged dependent variable at $\mathrm{t}-1$.
} 


\section{Findings}

We first turn to the paper's most basic question: do the mass media notice welfare state reforms?

Table 2 displays the results from the four time-series ordinary least squared (OLS) regression models specified in the section above. The explanatory variable for this question is all of the reform events combined (cutbacks, status quo, and expansions in either old age pensions or unemployment protection) in order to see the baseline reaction. We use the changes in the percentage of news on old age pensions and unemployment protection as the dependent variable in Models 1 and 2, and the changes in the number of news articles as the dependent variable in Models 3 and 4 . The effect is modest at best. In model 1, reform events increase the percentage of news articles, although the estimated effect is only borderline statistically significant and goes away in model 2 , where the monthly fixed effects are included. The picture is repeated in models 3 and 4 even though the coefficient is now estimated more precisely. All told, this is hardly solid evidence in favour of the proposition that the mass media indiscriminately report on welfare state reforms.

TABLE 2. Effect of any reform events

\begin{tabular}{lcccc}
\hline Media attention (DV): & \multicolumn{2}{c}{$\Delta \%$ Welfare news } & \multicolumn{2}{c}{$\Delta$ \# Welfare news } \\
& $(1)$ & $(2)$ & $(3)$ & $(4)$ \\
\hline$\Delta$ Number of reform events & $0.00534+$ & 0.00479 & $0.562^{*}$ & 0.441 \\
& $(1.87)$ & $(1.59)$ & $(2.04)$ & $(1.55)$ \\
$\Delta$ Media attention (t-1) & $-0.637^{* *}$ & $-0.652^{* *}$ & $-0.674^{* *}$ & $-0.681^{* *}$ \\
& $(-9.24)$ & $(-9.48)$ & $(-9.86)$ & $(-9.90)$ \\
$\Delta$ Media attention (t-2) & $-0.388^{* *}$ & $-0.416^{* *}$ & $-0.404^{* *}$ & $-0.430^{* *}$ \\
& $(-5.06)$ & $(-5.40)$ & $(-5.19)$ & $(-5.51)$ \\
$\Delta$ Media attention (t-3) & -0.0352 & -0.0595 & -0.0178 & -0.0315 \\
& $(-0.51)$ & $(-0.86)$ & $(-0.26)$ & $(-0.45)$ \\
$\Delta$ Media attention (t-12) & 0.0254 & & 0.0691 & \\
& $(0.44)$ & & $(1.18)$ & \\
Constant & 0.000562 & 0.0193 & 0.0853 & $2.289+$ \\
& $(0.14)$ & $(1.36)$ & $(0.22)$ & $(1.72)$ \\
\hline Monthly fixed effects & No & Yes & No & Yes \\
$\mathrm{N}$ & 215 & 224 & 215 & 224 \\
$\mathrm{R}^{2}$ & 0.327 & 0.365 & 0.364 & 0.407 \\
\hline
\end{tabular}

Note: $t$ statistics in parentheses; $+\mathrm{p}<0.10,{ }^{*} \mathrm{p}<0.05,{ }^{* *} \mathrm{p}<0.01$; the dependent variable (media attention) is the changes in the percentage of reform-relevant news articles in models 1 and 2 , and the changes in the number of news 
articles in models 3 and 4; in models 2 and 4, we include a dummy variable for each month of the year to account for seasonality.

Next, we want to explore the second question: do the mass media respond differently depending on the direction of the reform event? To that end, we decompose the reform event variable into two: the changes in the number of cutback reforms and the changes in the number of expansion reforms (leaving aside the few status quo reform events). Table 3 below shows results from our four models. The first two models use the changes in the percentage of welfare news as the dependent variable, while the last two take the changes in the number of such news as the dependent variable. The two models for each measure of media attention include the lagged dependent variable at t-12 (models 1 and 3) or monthly dummies (models 2 and 4) to account for seasonality; i.e. exactly as in Table 2.

The new results are much stronger than the previous ones, with cutbacks having a substantial and statistically significant effect and expansions having no effect at all. The results are reproduced for both measures of the dependent variables. The results for the number of news articles are more intuitive to interpret in a meaningful way; zooming in on them, we find an estimate cutback coefficient of around 1.5 in models 3 and 4. This implies that a single cutback leads to 1.5 more news article in the month of the reform. Given that the median number of news articles is six per month, this is $25 \%$ above a typical month's volume. In terms of the face validity of this estimate, it is worth noting that the median number of observed news articles in months with one or more cutbacks is eight. The estimated 1.5 additional news articles following a single cutback is, in other words, rather plausible given the actual distribution. 
TABLE 3. Effect of cutbacks and expansions individually

\begin{tabular}{l|cccc}
\hline Media attention (DV): & \multicolumn{2}{|c}{$\Delta \%$ Welfare news } & \multicolumn{2}{c}{$\Delta$ \# Welfare news } \\
& $(1)$ & $(2)$ & $(3)$ & $(4)$ \\
\hline$\Delta$ Cutback & $0.0148^{* *}$ & $0.0159^{* *}$ & $1.493^{* *}$ & $1.510^{* *}$ \\
& $(2.78)$ & $(2.89)$ & $(2.93)$ & $(2.92)$ \\
$\Delta$ Expansion & -0.00198 & -0.00405 & -0.173 & -0.432 \\
& $(-0.41)$ & $(-0.81)$ & $(-0.37)$ & $(-0.91)$ \\
$\Delta$ Media attention (t-1) & $-0.612^{* *}$ & $-0.628^{* *}$ & $-0.654^{* *}$ & $-0.664^{* *}$ \\
& $(-8.80)$ & $(-9.15)$ & $(-9.55)$ & $(-9.70)$ \\
$\Delta$ Media attention (t-2) & $-0.371^{* *}$ & $-0.393^{* *}$ & $-0.391^{* *}$ & $-0.411^{* *}$ \\
& $(-4.85)$ & $(-5.12)$ & $(-5.07)$ & $(-5.30)$ \\
$\Delta$ Media attention (t-3) & -0.0182 & -0.0450 & 0.00219 & -0.0147 \\
& $(-0.26)$ & $(-0.66)$ & $(0.03)$ & $(-0.21)$ \\
$\Delta$ Media attention (t-12) & 0.0115 & & 0.0604 & \\
& $(0.20)$ & & $(1.04)$ & \\
Constant & 0.000609 & 0.0190 & 0.0887 & $2.287+$ \\
& $(0.15)$ & $(1.36)$ & $(0.23)$ & $(1.73)$ \\
\hline Monthly fixed effects & No & Yes & No & Yes \\
$\mathrm{N}$ & 215 & 224 & 215 & 224 \\
$\mathrm{R}^{2}$ & 0.341 & 0.382 & 0.379 & 0.424 \\
\hline
\end{tabular}

Note: $\mathrm{t}$ statistics in parentheses; $+\mathrm{p}<0.10,{ }^{*} \mathrm{p}<0.05,{ }^{* *} \mathrm{p}<0.01$; the dependent variable (media attention) is the changes in the percentage of reform-relevant news articles in models 1 and 2, and the changes in the number of news articles in models 3 and 4; in models 2 and 4, we include a dummy variable for each month of the year to account for seasonality.

A follow-up question is, then: do the mass media respond differently to reforms to old age pensions and unemployment protection? As discussed in the theory section, there is reason to expect the mass media to report equally on old age pensions and unemployment protection, albeit for different reasons (the former being uniformly popular and the latter being highly contentious). To explore this, we rerun the models reported in Table 3, this time disaggregating the reform event data further into cutbacks and expansions for the two domains individually. A downside of this approach is that we push the statistical model to its limits because the dataset only includes 8 months with cutbacks in old age pensions and a meagre five months with expansions in unemployment protection. This is a straightforward consequence of the relative popularity of the two domains but means that precise estimations become trickier. 
These caveats aside, Table 4 reports the disaggregated results. The basic pattern in Table 3 is repeated, with cutbacks leading to more attention and expansions having no effect. Three of the estimated coefficients for cuts to old age pensions are only statistically significant at $\mathrm{p}<0.10$, but this is unsurprising given how few months have seen cutbacks in old age pensions. Assuming that the estimated coefficients for old age pension cutbacks are statistically significant, we see that one cutback leads to two additional news articles, which is an almost $30 \%$ increase in attention above the monthly average. The size of the effect is slightly smaller for unemployment protection, with around 1.5 more news articles in months with cutbacks. Overall, however, there is little indication that the mass media is more attentive to cuts to pensions than to unemployment protection. The data at hand does not allow us to investigate why this is the case, but one plausible explanation is that while cutbacks in both domains are newsworthy, they are newsworthy for different reasons: old age pension cutbacks are reported because they concern a very large segment of society, whereas cuts to unemployment protection are reported due to the polarised nature of public opinion. 
TABLE 4. Effects of cutbacks and expansions per domain

\begin{tabular}{l|cccc}
\hline Media attention (DV): & \multicolumn{2}{|c}{$\Delta \%$ Welfare news } & \multicolumn{2}{c}{$\Delta$ \# Welfare news } \\
& $(1)$ & $(2)$ & $(3)$ & $(4)$ \\
\hline$\Delta$ Cutback in pension & $0.0194+$ & $0.0195+$ & $2.210^{*}$ & $1.843+$ \\
& $(1.72)$ & $(1.73)$ & $(2.04)$ & $(1.73)$ \\
$\Delta$ Expansion in pension & -0.00261 & -0.00474 & -0.232 & -0.447 \\
& $(-0.47)$ & $(-0.85)$ & $(-0.44)$ & $(-0.85)$ \\
$\Delta$ Cutback in unemployment & $0.0150^{*}$ & $0.0170^{* *}$ & $1.457^{*}$ & $1.644^{* *}$ \\
& $(2.38)$ & $(2.67)$ & $(2.45)$ & $(2.73)$ \\
$\Delta$ Expansion in unemployment & -0.00743 & -0.0135 & -0.956 & -1.620 \\
& $(-0.48)$ & $(-0.86)$ & $(-0.65)$ & $(-1.08)$ \\
$\Delta$ Media attention (t-1) & $-0.615 * *$ & $-0.630^{* *}$ & $-0.651^{* *}$ & $-0.662^{* *}$ \\
& $(-8.79)$ & $(-9.19)$ & $(-9.51)$ & $(-9.69)$ \\
$\Delta$ Media attention (t-2) & $-0.422^{* *}$ & $-0.453^{* *}$ & $-0.450^{* *}$ & $-0.476^{* *}$ \\
& $(-5.23)$ & $(-5.64)$ & $(-5.54)$ & $(-5.83)$ \\
$\Delta$ Media attention (t-3) & -0.102 & $-0.148+$ & -0.0986 & -0.128 \\
& $(-1.25)$ & $(-1.84)$ & $(-1.19)$ & $(-1.55)$ \\
$\Delta$ Media attention (t-4) & $-0.131+$ & $-0.159^{*}$ & $-0.152^{*}$ & $-0.166^{*}$ \\
& $(-1.89)$ & $(-2.33)$ & $(-2.19)$ & $(-2.41)$ \\
$\Delta$ Media attention (t-12) & 0.0258 & & 0.0853 & \\
& $(0.44)$ & & $(1.44)$ & \\
Constant & 0.000669 & $0.0240+$ & 0.0997 & $2.851^{*}$ \\
& $(0.16)$ & $(1.71)$ & $(0.26)$ & $(2.15)$ \\
\hline Monthly fixed effects & No & Yes & No & Yes \\
$\mathrm{N}$ & 215 & 223 & 215 & 223 \\
$\mathrm{R}^{2}$ & 0.353 & 0.404 & 0.396 & 0.445 \\
\hline
\end{tabular}

Note: $t$ statistics in parentheses; $+\mathrm{p}<0.10,{ }^{*} \mathrm{p}<0.05,{ }^{* *} \mathrm{p}<0.01$; the dependent variable (media attention) is the changes in the percentage of reform-relevant news articles in models 1 and 2, and the changes in the number of news articles in models 3 and 4; in models 2 and 4, we include dummy variable for each month of the year to account for seasonality.

The last question in the paper concerns whether the visibility of reform events matters for news reporting: do the mass media report equally on 'visible' and 'invisible' policy instruments? The expectation is that relatively 'visible' reforms will get more attention than relatively 'invisible' reforms. To see if this is the case, we employ the visibility variable introduced previously, which gave each reform event a score based on its visibility (ranging from 1 for clearly invisible reforms to 5 for clearly visible). Based on this measure, we calculate the mean level of visibility of a given 
month's reform activities (for cutbacks and expansions, separately). ${ }^{5}$ Table 5 reports the findings from four regressions that replicate the setup of Table 3, with the exception of using the average 'visibility' scores of cutback and expansion reforms. Across all four models, we found the positive and statistically significant coefficients for cutbacks. This indicates that visible cutback reforms are more likely to grasp the attention of the mass media. For example, the results from models 3 and 4 suggest that the newspaper produces 1.5 more news articles when the average visibility score of the cutback events becomes higher by one unit on the scale. In other words, there will be three more news articles in a given month if the cutbacks are quite visible (scored 4) compared to a month where cutbacks are on average quite invisible (scored 2), ceteris paribus.

TABLE 5. Effect of visibility of cutbacks and expansions

\begin{tabular}{|c|c|c|c|c|}
\hline \multirow[t]{2}{*}{ Media attention (DV): } & \multicolumn{2}{|c|}{$\Delta \%$ Welfare news } & \multicolumn{2}{|c|}{$\Delta \#$ Welfare news } \\
\hline & $(1)$ & (2) & (3) & (4) \\
\hline$\Delta$ Mean visibility of cutbacks & $\begin{array}{c}0.0132 * \\
(2.41)\end{array}$ & $\begin{array}{c}0.0142 * \\
(2.54)\end{array}$ & $\begin{array}{c}1.465 * * \\
(2.81)\end{array}$ & $\begin{array}{c}1.445^{* *} \\
(2.73)\end{array}$ \\
\hline$\Delta$ Mean visibility of expansions & $\begin{array}{c}-0.00371 \\
(-0.72)\end{array}$ & $\begin{array}{c}-0.00692 \\
(-1.30)\end{array}$ & $\begin{array}{l}-0.358 \\
(-0.73)\end{array}$ & $\begin{array}{l}-0.691 \\
(-1.38)\end{array}$ \\
\hline$\Delta$ Media attention $(\mathrm{t}-1)$ & $\begin{array}{c}-0.630 * * \\
(-9.13)\end{array}$ & $\begin{array}{c}-0.644 * * \\
(-9.55)\end{array}$ & $\begin{array}{c}-0.665 * * \\
(-9.81)\end{array}$ & $\begin{array}{c}-0.674 * * \\
(-9.99)\end{array}$ \\
\hline$\Delta$ Media attention $(\mathrm{t}-2)$ & $\begin{array}{c}-0.430 * * \\
(-5.32)\end{array}$ & $\begin{array}{c}-0.463 * * \\
(-5.76)\end{array}$ & $\begin{array}{c}-0.457 * * \\
(-5.62)\end{array}$ & $\begin{array}{c}-0.484 * * \\
(-5.92)\end{array}$ \\
\hline$\Delta$ Media attention $(\mathrm{t}-3)$ & $\begin{array}{l}-0.111 \\
(-1.36)\end{array}$ & $\begin{array}{c}-0.154+ \\
(-1.91)\end{array}$ & $\begin{array}{l}-0.108 \\
(-1.31)\end{array}$ & $\begin{array}{l}-0.133 \\
(-1.62)\end{array}$ \\
\hline$\Delta$ Media attention $(\mathrm{t}-4)$ & $\begin{array}{c}-0.131+ \\
(-1.90)\end{array}$ & $\begin{array}{c}-0.158 * \\
(-2.33)\end{array}$ & $\begin{array}{c}-0.155^{*} \\
(-2.25)\end{array}$ & $\begin{array}{c}-0.165^{*} \\
(-2.41)\end{array}$ \\
\hline$\Delta$ Media attention $(\mathrm{t}-12)$ & $\begin{array}{c}0.0284 \\
(0.49)\end{array}$ & & $\begin{array}{c}0.0828 \\
(1.42)\end{array}$ & \\
\hline Constant & $\begin{array}{c}0.0006 \\
(0.16) \\
\end{array}$ & $\begin{array}{c}0.0234+ \\
(1.67) \\
\end{array}$ & $\begin{array}{c}0.0980 \\
(0.25) \\
\end{array}$ & $\begin{array}{c}2.779 * \\
(2.10)\end{array}$ \\
\hline Monthly fixed effects & No & Yes & No & Yes \\
\hline $\mathrm{N}$ & 215 & 223 & 215 & 223 \\
\hline $\mathrm{R}^{2}$ & 0.343 & 0.394 & 0.387 & 0.437 \\
\hline
\end{tabular}

Note: $t$ statistics in parentheses; $+p<0.10, * p<0.05, * * p<0.01$; the dependent variable (media attention) is the changes in the percentage of reform-relevant news articles in models 1 and 2, and the changes in the number of news articles in models 3 and 4; in models 2 and 4, we include a dummy variable for each month of the year to account for seasonality.

\footnotetext{
${ }^{5}$ For example, if there were three expansion events in the given month with visibility scores 2,5 , and 5 , we regard the average visibility of the month's expansion reforms as quite visible $([2+5+5] / 3=4)$.
} 
We now revisit the hypotheses outlined above. Our initial expectation (H1 'relevance') was that welfare reforms would attract mass media attention, as the welfare state is important to big groups of news consumers; alternatively, there is also reason to believe that such reforms would not receive attention, as they tend to be complicated (H2 'simplicity'). We then posited that there would be a negativity bias, with cutbacks receiving more attention than expansions (H3 'negativity'), and that this effect would remain equal across the two policy domains (H4). We further posited that visible cutbacks would receive more attention than all other reform events (H5 'simplicity + negativity'). In a sense, the latter three hypotheses proved so successful that H1 and $\mathrm{H} 2$ turned out to be too simplistic. Our results support both $\mathrm{H} 1$ and $\mathrm{H} 2$, but only under the conditions specified by H3 and H5. The mass media definitely report on welfare state reforms, but this reporting comes with a hefty bias. Visible cutbacks get priority.

\section{Conclusion}

The puzzle of lacking voter reactions to welfare state reform has preoccupied scholars for some time: how are politicians able to escape punishment for welfare state cutbacks? One possibility is that the mass media simply do not report on these kinds of reforms consistently. Without mass media attention, it is highly unlikely that most voters will ever hear about parliamentary decisions. To explore this, we collected two datasets - one with information on reform events in old age pensions and unemployment protection and another with information on mass media attention to these two domains - and estimated a set of time series regressions to study whether the former predicts the latter. We found very substantial effects, but only for cutbacks and especially for 'visible' ones. These biases are easy to understand given the focus on easy-to-understand and negative news stories in the mass media, so we believe our results are robust both in the empirical and theoretical sense. 
The findings have important implications for the welfare state literature. For one thing, they suggest that the logic of the new politics approach is correct: the type of reform activity matters for the likelihood of the mass media reporting on it. The fact that expansions get less airtime than cutbacks suggests that it is much easier to be blamed for hurting the voters than to get credit for pleasing them. The new politics approach, as noted, also appears to be right in expecting the visibility of reforms to matter. Yet this points to a way out of the conundrum for reform-minded politicians. If the mass media tend to pay more attention to 'visible' than 'invisible' reforms, then the obvious answer for politicians would be to rely on the invisible type when retrenching the welfare state and the visible type when expanding it. Indeed, this is exactly the pattern documented by Jensen et al. (2017). This might be one reason why Giger and her collaborators have found such mixed effects of welfare state reforms on government vote shares: on balance, governments are able to avoid too much blame for reforms by expertly employing comparably 'invisible' cutbacks that the mass media are likely to ignore and the voters are therefore hardly able to learn about.

The findings also highlight several issues for future research. First, our finding that the mass media are responsive to cutbacks does not necessarily imply that a majority of voters pick up the information about welfare cutbacks nor that they deliberately decide votes solely on that basis. Rather, this finding merely suggests a precondition for voter reaction. Investigating which news stories filter through and impact public opinion will be an important next step. Second, we only studied Britain. As we explained, there is good reason for doing so, but expanding the investigation to other national settings would obviously be worthwhile. Third, our data only examines the volume of attention, not its content. There is an assumption in the welfare state literature that more public attention to cutbacks is negative for governments, but this may not be true all of the time; especially regarding unemployment protection, with its polarised public opinion climate, it is imaginable that the politicians responsible have deliberately framed some of the cutbacks as positive (e.g. reducing benefits to help finance tax cuts). However, more labour- 
intensive, future research ought to explore more systematically how politicians frame welfare state reforms and whether these frames map onto mass media coverage.

\section{Acknowledgements}

We would like to thank Lasse Leipziger and Niels Christian Roesdahl for excellent research assistance. 


\section{References}

Aardal, Bernt, and Pieter van Wijnen (2005). 'Issue Voting', in Jacques Thomassen (ed.), The European Voter: A Comparative Study of Modern Democracies. Oxford: Oxford University Press, 192-212.

Allan, James P., and Lyle Scruggs (2004). 'Political Partisanship and Welfare State Reform in Advanced Industrial Societies', American Journal of Political Science, 48:3, 496-512. Armingeon, Klaus, and Nathalie Giger (2008). 'Conditional Punishment: A Comparative Analysis of the Electoral Consequences of Welfare State Retrenchment in OECD Nations, 1980-2003', West European Politics, 31:3, 558-580.

Clasen, Jochen, and Daniel Clegg (2007). 'Levels and Levers of Conditionality: Measuring Change Within Welfare States', in Jochen Clasen and Nico Siegel (eds.), Investigating Welfare State Change: The 'Dependent Variable Problem' in Comparative Analysis. Cheltenham: Edward Elgar, 166-197.

Curtice, John (2017). The Role of Government: British Social Attitudes Survey 34. Downloaded from http://www.bsa.natcen.ac.uk/latest-report/british-social-attitudes-34/role-ofgovernment.aspx. Accessed 24 October 2017.

Elmelund-Præstekær, Christian, Michael B. Klitgaard, and Gijs Schumacher (2015). 'What Wins Public Support? Communicating or Obfuscating Welfare State Retrenchment', European Political Science Review, 7:03, 427-450.

Esping-Andersen, Gøsta (1990). The Three Worlds of Welfare Capitalism. Princeton: Princeton University Press.

Fogarty, Brian J. (2005). 'Determining Economic News Coverage', International Journal of Public Opinion Research, 17:2, 149-172.

Gans, Herbert J. (1979). Deciding What's News: A Study of CBS Evening News, NBC Nightly News, Newsweek, and Time. Chicago: Northwestern University Press.

Giger, Nathalie, and Moira Nelson (2011). 'The Electoral Consequences of Welfare State Retrenchment: Blame Avoidance or Credit Claiming in the Era of Permanent Austerity?', European Journal of Political Research, 50:1, 1-23.

Giger, Nathalie, and Moira Nelson (2013). 'The Welfare State or the Economy? Preferences, Constituencies, and Strategies for Retrenchment', European Sociological Review, 29:5, 1083-1094.

Golding, Peter, and Philip Elliott (1979). Making the News. London: Longman. 
Gujarati, Damodar N. (2003). Basic Econometrics, Fourth Edition. Boston: McGraw-Hill. Jensen, Carsten (2014). The Right and the Welfare State. New York: Oxford University Press. Jensen, Carsten, Christoph Arndt, Seonghui Lee, and Georg Wenzelburger. 2017. 'Policy Instruments and Welfare State Reform', Journal of European Social Policy. Early view.

John, Peter, Anthony Bertelli, Will Jennings, and Shaun Bevan (2013). Policy Agendas in British Politics. Springer.

Jones, Bryan D., and Frank R. Baumgartner (2005). The Politics of Attention: How Government Prioritizes Problems. Chicago: University of Chicago Press.

Jones, Bryan D., Tracy Sulkin, and Heather A. Larsen (2003). 'Policy Punctuations in American Political Institutions', American Political Science Review, 97:1, 151-169.

Jæger, Mads Meier (2011). 'Do We All (Dis)like the Same Welfare State? Configurations of Public Support for the Welfare State in Comparative Perspective', in Jon Kvist, Johan Fritzell, Bjørn Hvinden, and Olli Kangas (eds.), Changing Social Inequality: The Nordic Model in the 21st Century. Bristol: Policy Press, 45-68.

Korpi, Walter, and Joakim Palme (2003). 'New Politics and Class Politics in the Context of Austerity and Globalization: Welfare State Regress in 18 countries, 1975-95', American Political Science Review, 97:3, 425-446.

Lindbom, Anders (2010). 'Media News Evaluation and Welfare Retrenchment: The Untransparent Cutbacks of the Housing Allowance', Scandinavian Political Studies, 33:3, 207-223.

Matthews, J. Scott, Mark Pickup, and Fred Cutler (2012). 'The Mediated Horserace: Campaign Polls and Poll Reporting', Canadian Journal of Political Science, 45(2): 261-287.

Patterson, Thomas (1994). Out of Order. New York: Vintage.

Pierson, Paul (1994). Dismantling the Welfare State? Reagan, Thatcher, and the Politics of Retrenchment. Cambridge: Cambridge University Press.

Pierson, Paul (1996). 'The New Politics of the Welfare State', World Politics, 48:2, 143-179.

Pierson, Paul (2001). 'Coping with Permanent Austerity: Welfare State Restructuring in Affluent Democracies', in Paul Pierson (ed.), The New Politics of the Welfare State. Oxford: Oxford University Press, 410-456.

Shoemaker, Pamela J., and S. D. Reese (2013). Mediating the Message in the 21st Century: A Media Sociology Perspective. London: Routledge.

Soroka, Stuart N. (2006). 'Good News and Bad News: Asymmetric Responses to Economic Information', Journal of Politics, 68:2, 372-385. 
Soroka, Stuart N. (2014). Negativity in Democratic Politics: Causes and Consequences. Cambridge and New York: Cambridge University Press.

Soroka, Stuart N., D. A. Stecula, and C. Wlezien (2015). 'It's (Change in) the (Future) Economy, Stupid: Economic Indicators, the Media, and Public Opinion', American Journal of Political Science, 59:2, 457-474.

Van Oorschot, Wim (2006). 'Making the Difference in Social Europe: Deservingness Perceptions among Citizens of European Welfare States', Journal of European Social Policy 16:1, 23-42. 